\title{
Characterisation of plant-parasitic nematodes Helicotylenchus digonicus and $H$. vulgaris from the rhizosphere of grapevines in Crimea, Russia
}

\author{
Svetlana Lychagina ${ }^{1, *}$, Yakov Volkov ${ }^{2}$, Marina Volkova $^{2}$, Tatyana Kolganova ${ }^{3}$, and Sergei \\ Tabolin ${ }^{1,4}$ \\ ${ }^{1}$ Federal State Budget Scientific Institution "Federal Scientific Centre VIEV" (FSC VIEV), Russian \\ Academy of Sciences, Bolshaya Cheremushkinskaya Street 28, Moscow, 117218, Russia \\ ${ }^{2}$ All-Russian National Research Institute of Viticulture and Winemaking "Magarach", Russian \\ Academy of Sciences, Kirov Street 31, Yalta, 298600, Russia \\ ${ }^{3}$ Institute of Bioengineering, Research Centre of Biotechnology, Russian Academy of Sciences, \\ Leninskiy Prospekt 33, bld. 2, Moscow, 119071, Russia \\ ${ }^{4}$ A.N. Severtsov Institute of Ecology and Evolution, Russian Academy of Sciences, Leninskiy \\ Prospekt 33, Moscow, 119071, Russia
}

\begin{abstract}
During 2016-2020, about 120 soil samples were collected from the rhizosphere of grapes in different vineyards of the Central and Southern regions of Crimea. Two morphologically close nematode species, Helicotylenchus digonicus and Helicotylenchus vulgaris, were found at all sampling sites in the Yalta, Sevastopol, Simferopol and Bakhchisarai districts. Morphologically, these species could be differentiated by the stylet length and the shape of tails. In addition, these species have significant differences in sequences of the D2-D3 expansion segments of the $28 \mathrm{~S}$ rRNA.
\end{abstract}

\section{Introduction}

One of the main branches of agriculture in the Republic of Crimea is viticulture. In 2020, the total area of vineyards in the republic was about 19 thousand hectares, of which 16 thousand were fruit-bearing. However, the yield from these vineyards remains very low. In 2020, the average yield in Crimea was about 56 centners per hectare, while the normal yield from the specialized plantations of industrial vineyards is considered to be 120-150 centners per hectare. It is known that plant-parasitic nematodes can seriously reduce the yield of grapes and even cause the death of individual plants. Despite this, data on the species composition of plant-parasitic nematodes and their distribution in vineyards of the Republic of Crimea are very limited.

During routine nematological surveys conducted in 2016-2020 in the Crimean Peninsula, Helicotylenchus digonicus Perry, 1959 and Helicotylenchus vulgaris Yuen, 1964 were the most frequently encountered spiral nematodes in the rhizosphere of grapevines.

\footnotetext{
* Corresponding author: lychagina-svetlana@rambler.ru
} 
These two species were found at all sampling sites in the Yalta, Sevastopol, Simferopol and Bakhchisarai districts.

\section{Materials and methods}

The soil samples for this study were collected near the village of Nekrasovka in the Bakhchisarai district $(44.754265 \mathrm{~N}, 33.687089$ E). Nematodes were extracted using a modification of the funnel method [1]. For morphological studies, the nematodes were killed with hot water, fixed in a 5-\% formalin solution, and mounted in glycerine on slides using the Seinhorst technique [2]. Molecular studies were performed using the scientific equipment of the Core Research Facility of the "Bioengineering" Centre (Moscow, Russia). For this work, nematodes frozen in distilled water were used. Their total DNA was extracted from several specimens using the Wizard kit (Promega, USA) according to the manufacturer's instructions. The forward Nem_18S_F (5'-CGC GAA TRG CTC ATT ACA ACA GC-3') and the reverse Nem_18S_R (5'-GGG CGG TAT CTG ATC GCC-3') primers were used for the amplification of the fragment of the $18 \mathrm{~S}$ rRNA gene. The D2-D3 expansion segments of the 28S rRNA gene were amplified using the forward D2A (5'-CAA GTA CCG TGA GGG AAA GTT G-3') and the reverse D3B (5'-TCG GAA GGA ACC AGC TAC TA-3') primers. The partial cytochrome c oxidase subunit 1 gene was amplified with the forward primer JB3 (5'-TTT TTT GGG CAT CCT GAG GTT-3') and the reverse primer JB5 (5'-AGC ACC TAA ACT TAA AAC ATA ATG AAA ATG-3'). The amplifications were performed in a Tetrad thermal cycler (Bio-Rad, USA). PCR products were purified using the WizardPCRPreps kit (Promega, USA). The sequencing of the PCR products was carried out with the same primers using the genetic analyser "ABI 3730" (Applied Biosystems, USA). Low-quality segments of sequences at the 5 ' and 3 ' ends were removed. The newly obtained sequences of $H$. digonicus were submitted to the GenBank database under accession numbers MW881576 (18S rRNA), MW881577 (28S rRNA) and MW881605 (cox1). The newly obtained sequences of $H$. vulgaris were submitted to the GenBank database under accession numbers MW881606 (18S rRNA), MW881607 (28S rRNA) and MW881650 (cox1). The dendrogram was constructed using the neighbourjoining method [3]. The 28S rRNA sequence of Criconemoides informis Micoletzky, 1922, which was also found in the rhizosphere of grapevines in Crimea [4], was used as the outgroup.

\section{Results and discussion}

Description of $\boldsymbol{H}$. digonicus. Female. Body spiral. Lip region anteriorly flattened and continues with body contour, with four to five annules. Cuticle distinctly annulated with annules approximately $1 \mu \mathrm{m}$ wide. Lateral field consists of four incisures. Stylet cone about equal in length to shaft, knobs anteriorly flattened or slightly indented, $4-5 \mu \mathrm{m}$ across. Position of dorsal pharyngeal gland opening (DGO) about 8-10 $\mu \mathrm{m}$ posterior to stylet knobs. Median bulb ovoid. Hemizonid located 1 to 3 annules anterior to excretory pore. Excretory pore opening opposite isthmus. Intestine contains dense spherical granules. Reproductive system didelphic-amphidelphic. Rectum 0.9-1 times anal body diameter long. Phasmid located three to six annules anterior to anus. Tail conoid with curvature on dorsal side and tapering to a point ventrally but flattening somewhat distally (Fig. 1). Males were not found.

Remarks. The morphological characteristics of the Bakhchisarai population of $H$. digonicus resemble the original description of this species [5]. The studied specimens differ 
from the morphologically close species Helicotylenchus minzi by the tip of the tail and the absence of males in the population.

Molecular characterisation. The sequences of the 18S rRNA gene, the D2-D3 expansion segments of the 28S rRNA gene, and the COI gene obtained from different individuals in this study were identical within each marker. The sequences of the $18 \mathrm{~S}$ rRNA gene of the studied specimens were most similar to $H$. digonicus from Idaho, USA (KM603517), with 99.52\% similarity and $H$. digonicus from Xinjiang, China (MT856446), Helicotylenchus minzi from Washington, USA (KM603528), with 99.52\% similarity, and share $99.40 \%$ similarity with Helicotylenchus platyurus (KJ869401), Helicotylenchus varicaudatus from Portugal (HM237044) and other populations of Helicotylenchus minzi.

The sequences of the D2-D3 expansion segments of the 28S rRNA gene were most similar to the $H$. digonicus sequence from Portugal (MT232565), with 99.82\% similarity, $H$. digonicus from Iran (KM347963), with 99.39\% similarity, H. digonicus from China (MT872099), with 99.08\% similarity, and Helicotylenchus minzi from China (MT856990), with $98.62 \%$ similarity.

The sequences of the COI gene were most similar with sequences of $H$. digonicus from Poland (MG663103), with 89.58\% similarity, and share less similarity with other sequences of hoplolaimid nematodes deposited in the GenBank.

Table 1. Measurements of H. digonicus and H. vulgaris from the Bakhchisarai district, Crimea. Measurements are in $\mu \mathrm{m}$ and in the form: mean \pm standard deviation (range).

\begin{tabular}{|c|c|c|}
\hline Character & H. digonicus $(\mathrm{n}=15)$ & H. vulgaris $(\mathrm{n}=15)$ \\
\hline Body length $(\mathrm{L})$ & $647.5 \pm 93.6(500-848)$ & $750 \pm 74.8(625.6-861.9)$ \\
\hline $\mathrm{a}=\mathrm{L} / \mathrm{MBD}$ & $26.4 \pm 2.3(22-31.3)$ & $27.4 \pm 1.7(25-31.3)$ \\
\hline $\begin{array}{c}\mathrm{b}^{\prime}=\mathrm{L} / \text { Anterior end to the } \\
\text { end of esophageal gland }\end{array}$ & $4.9 \pm 0.5(4.0-5.4)$ & $5.0 \pm 0.35(4.5-5.7)$ \\
\hline $\mathrm{c}=$ L/Tail length & $50.6 \pm 5.8(42-52.6)$ & $57.5 \pm 9.4(46.1-76.7)$ \\
\hline $\mathrm{c}^{\prime}=$ Tail length/ABD & $1.04 \pm 0.12(0.77-1.22)$ & $0.88 \pm 0.13(0.63-1.04)$ \\
\hline $\begin{array}{c}\text { V = Anterior end to } \\
\text { vulva/L } \times 100\end{array}$ & $63.4 \pm 1.5(61.1-67.0)$ & $61.4 \pm 1.4(57.7-63.1)$ \\
\hline Stylet length & $25.7 \pm 1.2(24-29)$ & $30.2 \pm 0.6(28.7-31.3)$ \\
\hline $\begin{array}{c}\text { Anterior end to secretory- } \\
\text { excretory pore }\end{array}$ & $107.7 \pm 10.3(84-127.6)$ & $111.8 \pm 6.8(95.9-124)$ \\
\hline Tail length & $12.8 \pm 2.1(9.5-15.3)$ & $13.2 \pm 1.8(11-16.2)$ \\
\hline Tail annuli number & $8.6 \pm 0.75(8-10)$ & $8.2 \pm 1.0(7-10)$ \\
\hline \multicolumn{2}{|c}{} \\
\hline
\end{tabular}



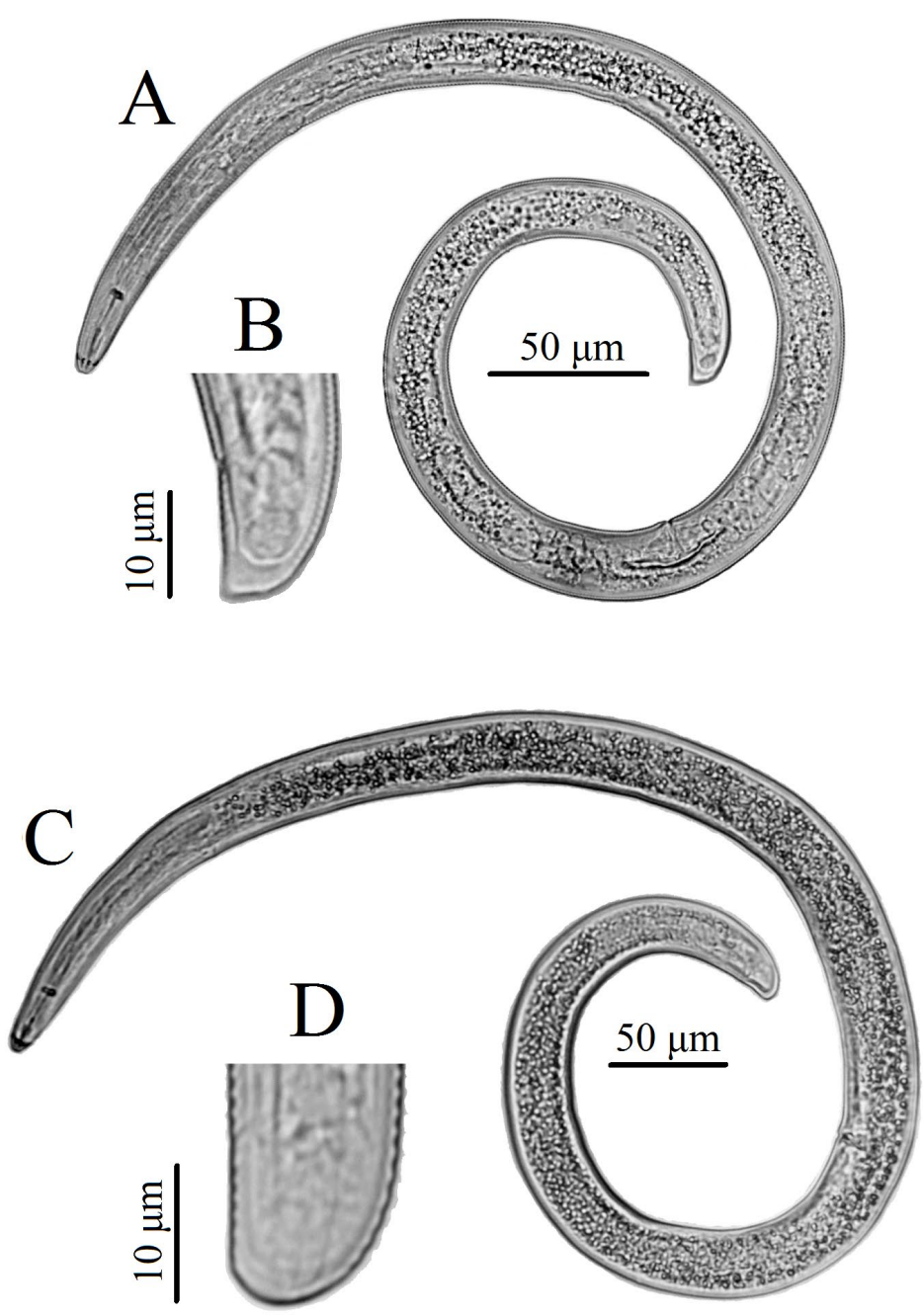

Fig. 1. Light micrographs of H. digonicus: (A) Entire female, (B) Tail region and H. vulgaris: (C) Entire female, (D) Tail region.

Description of $\boldsymbol{H}$. vulgaris. Female. Body spiral. Lip region anteriorly flattened and continues with body contour, with four to five annules. Cuticle distinctly annulated with annules approximately 1.3-1.7 $\mu \mathrm{m}$ wide. Lateral field consists of four incisures. Stylet cone about equal in length to shaft, knobs anteriorly concave, 5-6 $\mu \mathrm{m}$ across. Position of dorsal pharyngeal gland opening (DGO) about 10-12 $\mu \mathrm{m}$ posterior to stylet knobs. Median bulb ovoid. Hemizonid 1-2 annules long, located one to three annules anterior to excretory pore. Excretory pore opening posterior to nerve ring. Intestine contains dense spherical granules. Reproductive system didelphic-amphidelphic. Tail short, terminus blunt or obliquely truncated (Fig. 1). Males were not found.

Remarks. The morphological characteristics of the Bakhchisarai population of $H$. vulgaris resemble the original description [6] and some other descriptions of this species [7, 8]. 
Molecular characterisation. The sequences of the 18S rRNA gene, the D2-D3 expansion segments of the 28S rRNA gene, and the COI gene obtained from different individuals in this study were identical within each marker. The sequences of the $18 \mathrm{~S}$ rRNA gene of the studied specimens were identical with Helicotylenchus digitiformis (KJ869398) and $H$. digonicus (KJ869396), were most similar with H.vulgaris (KJ869393), with 99.88\% similarity, Helicotylenchus scoticus (KM014492), with $99.77 \%$ similarity, and Helicotylenchus pseudodigonicus (KJ869407), with 99.65\% similarity.

The sequences of the D2-D3 expansion segments of the 28S rRNA gene were most similar to the H. vulgaris sequence from Greece (MG770483) and H.vulgaris from Iran (KU722388), with $99.66 \%$ similarity. In the studied nematode populations, sequences of the 28S rRNA gene of $H$. vulgaris share $93.3 \%$ similarity with H. digonicus (Fig. 2).

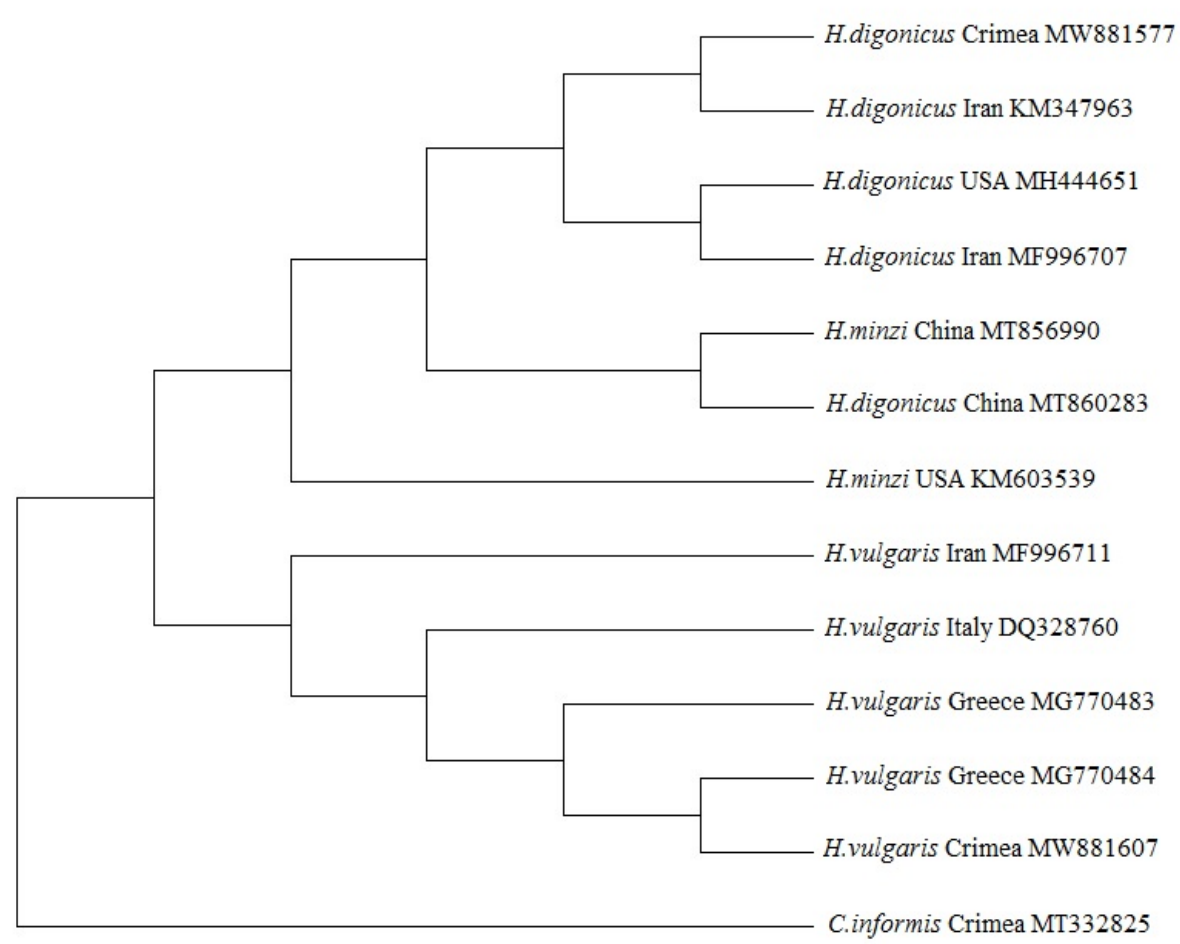

Fig. 2. Similarity of sequences of the D2-D3 expansion segments of the 28S gene of H. digonicus and H. vulgaris from the Bakhchisarai district with the most similar sequences deposited in the GenBank.

Despite the wide geographical distribution of H. vulgaris, as it is known from the literature, there are no cox 1 sequences of this species in the GenBank. The sequences of the COI gene were most similar to Helicotylenchus varicaudatus from Belgium (MN782380), with $88.48 \%$ similarity, and was less similar with other hoplolaimid sequences deposited in the GenBank.

\section{Conclusion}

As a result of the conducted work, it was found that the Crimean populations of morphologically similar species of $H$. digonicus and $H$. vulgaris can be distinguished by 1 ) the length of the stylet, 2) the shape of the tail, and 3) the width of the cuticle annules. The molecular diagnostics of these species should be carried out using the D2-D3 expansion 
segments of the $28 \mathrm{~S}$ gene. The sequences of the $18 \mathrm{~S}$ gene are not suitable for this work due to the presence of large fragments identical for many species of this genus. The sequences of the COI gene are variable, so they are also not suitable for the accurate identification of these species.

\section{Acknowledgements}

The work was carried out within the framework of the Program of fundamental scientific research of the state academies of sciences on the project FNSE-2019-0009 without attracting additional funding sources.

\section{References}

1. G. Baermann, Tijdschrift voor diergeneeskunde 57, 131-137 (1917)

2. J. W Seinhorst, Nematologica 4, 57-69 (1959)

3. N. Saitou and M. Nei, Molecular Biology and Evolution 4, 406-425 (1987)

4. S. B. Tabolin, V.D. Migunova, Y.A. Volkov, M.V. Volkova, Russian Journal of Nematology 28, 79-80 (2020)

5. V. G. Perry, H. M. Darling, G. Thorne, Research bulletin, Agricultural Experiment Station, University of Wisconsin 207, 24 (1959)

6. P. H. Yuen, Nematologica 10, 373-387 (1964)

7. S. A. Sher, Nematologica, 12, 1-56 (1966)

8. W. M. Wouts \& K.W.L. Knight, New Zealand Journal of Zoology, 20, 133-136 (1993) 